\title{
Estimation of Curie point depths and heat flow from Ardebil province, Iran, using aeromagnetic data
}

\author{
Allahyar Khojamli ${ }^{1}$ - Faramarz Doulati Ardejani ${ }^{2} \cdot$ Ali Moradzadeh $^{2}$. \\ Ali Nejati Kalate ${ }^{3}$ • Amin Roshandel Kahoo ${ }^{3}$ - Soheil Porkhial ${ }^{4}$
}

Received: 12 March 2015 / Accepted: 26 February 2016/Published online: 27 April 2016

(C) The Author(s) 2016. This article is published with open access at Springerlink.com

\begin{abstract}
This study attempts to estimate the Curie point depth (CPD) using the centroid and forward modelling of the spectral peak methods in the Sabalan geothermal field in Ardabil, NW of Iran. The reduced-to-pole aeromagnetic data were divided into 18 overlapping blocks of the sizes of $100 \times 100 \mathrm{~km}$. In the centroid method, the average depth to the top of the deepest crustal block, $Z_{\mathrm{t}}$, was first computed by linear fitting to the second longest wavelength segment of the power spectrum of aeromagnetic data. Then, depth to the centroid of the deepest crustal block, $Z_{0}$, was computed by linear fitting to the longest wavelength segment of the power spectrum of the aeromagnetic data. The depth to the magnetic bottom was obtained from $Z_{\mathrm{b}}=2 Z_{0}-Z_{\mathrm{t}}$. In the forward modelling of the spectral peak method, the modelled spectra fitted to the observed spectrum iteratively and $Z_{\mathrm{t}}$ and $Z_{\mathrm{b}}$ were finally estimated. According to the obtained results, the CPD
\end{abstract}

Allahyar Khojamli

a.khojamli.g@gmail.com

Faramarz Doulati Ardejani

fdoulati@ut.ac.ir

Ali Moradzadeh

a_moradzadeh@ut.ac.ir

Ali Nejati Kalate

nejati@shahroodut.ac.ir

Faculty of Engineering, Malayer University, Hamadan, Iran

2 School of Mining, College of Engineering, University of Tehran, Tehran, Iran

3 Faculty of Mining, Petroleum and Geophysics, Shahrood University of Technology, Shahrood, Iran

4 Renewable Energy Organization of Iran (SUNA), Tehran, Iran varies from 10 to $18.6 \mathrm{~km}$. The Curie temperature of magnetite was used to determine the thermal gradient and the heat flow in the area. The study area is found to have a great energy potential in the west, northwest and the southwest of the Sabalan with shallow CPD, high geothermal gradient and heat flow.

Keywords Curie point depth · Aeromagnetic - Geothermal . Sabalan $\cdot$ Spectral analysis

\section{Introduction}

The Curie point (approximately $580^{\circ} \mathrm{C}$ for magnetite at atmospheric pressure) is the temperature at which the spontaneous magnetization vanishes and magnetic minerals show paramagnetic susceptibility. The depth at which temperature reaches the Curie point is assumed to be the bottom of the magnetized bodies in the earth crust. Curie point temperature varies from region to region depending on the geology and the mineralogical content of the rocks. Therefore, one can normally expect shallow Curie point depth (CPD) at the regions which have geothermal potential, young volcanisms and thin crust (Aydin and Oksum 2010). The assessment of the variations in the Curie depth of an area can provide valuable information about the regional temperature distribution at depth and the potential of subsurface geothermal energy (Tselentis 1991).

The idea of using aeromagnetic data to estimate CPD is not new, and it has been widely applied to various parts of the world. Bhattacharyya and Leu (1975) mapped Curie point isothermal surface for geothermal reconnaissance of the Yellowstone National Park in USA. In this area, CPD was estimated 4-8 km. Tselentis (1991) calculated CPD in Greece from aeromagnetic and heat flow data. Tselentis's objective was to understand the nature and extent of the regional 
geothermal system at a depth beneath the area of Greece by constructing the Curie isotherms. The results of his investigations revealed that the CPD varies considerably beneath Greece, reaching $20 \mathrm{~km}$ towards western Greece and about $10 \mathrm{~km}$ beneath the Aegean. In East and Southeast Asia, CPD was determined based on the spectral analysis of magnetic anomaly data by Tanaka et al. (1999). In this study, they used many heat flow data from the boreholes. The estimated CPD for this area using centroid method varied from 9 to $46 \mathrm{~km}$. In addition, they predicted CPD from heat flow data. The CPD estimated from the heat flow data were very similar to the results of the CPD analysis of magnetic data. Dolmaz et al. (2005) concluded that the study of earth crust's thermal structure in SW of Turkey is useful to determine modes of deformation, depths of brittle and ductile deformation zones and regional heat flow variations. Karastathis et al. (2010) found the deep origin of the geothermal fields and volcanic centres in central Greece, by combining a travel-time inversion of a micro-seismic dataset together with a CPD analysis based on the aeromagnetic data. They also found that a possible magma chamber can be presumed by detecting a low seismic velocity volume at depths below $8 \mathrm{~km}$ and the CPD estimation at about 7-8-km depth as well.

Bansal et al. (2011) estimated the bottom depth of magnetic sources in Germany using aeromagnetic data. At first, they proposed a modified centroid method to estimate the depth to the bottom of magnetic sources. To assess the calculated bottom depth of magnetic sources, the results were then compared with the heat flow density data. Saleh et al. (2012) estimated CPD and heat flow map for Northern Red Sea rift of Egypt. Their aim was to map the CPD based on the spectral analysis of the aeromagnetic data. The CPD varied from 5 to $20 \mathrm{~km}$. The shallowest CPD of $5 \mathrm{~km}$ (associated with the high heat flow) was suggested a promising area for geothermal exploration. Eletta and Udensi (2012) investigated the CPD isotherm from the aeromagnetic data to prepare a preliminary potential map of geothermal resources in the Eastern Sector of Central Nigeria. They showed that the high prospect areas are located in the south-west parts of the study area. Obande et al. (2014) applied spectral analysis of aeromagnetic data for geothermal prospecting in the north-east Nigeria. They estimated the top and the centroid depths of magnetic source from the power spectrum. The obtained results were subsequently used to estimate the bottom depth. The range of CPD varies from 6 to $12 \mathrm{~km}$ according to the heat flow and CPD values of the study area wherein the highest heat flow value and the shallowest CPD occurred near the thermal springs. The Wikki warm spring area was found to have a great energy potential with a shallow CPD and very high heat flow values.

The geological and geophysical evidences together with the presence of several hot water springs in Ardebil province in the NW of Iran indicate that the area could have a high geothermal energy potential. Besides, the review of the published materials shows that no comprehensive aeromagnetic data analysis exists to prove the geothermal potential of the region. So, any study regarding to locate geothermal potential zones in such a vast region is highly important in the early stage of a geothermal exploration program. Therefore, this paper attempts to apply Centroid depth and forward modelling of the spectral peak methods of the aeromagnetic data to determine CPD in the main part of the Ardebil province particularly around the Sabalan mountain area. The heat flow values are then estimated and mapped to assess further geothermal zones.

\section{Geological settings}

Ardabil province is a famous tourist destination in Iran. Its pleasant climate especially in spring and summer seasons is always worthy for most visitors and residents. Several hot springs, with temperatures varied between 20 and $85^{\circ} \mathrm{C}$, exist in Ardabil, which there are mostly around the Sabalan Mountain (Mt. Sabalan). The Sabalan geothermal area (Figs. 1 and 2) which is now under investigation for geothermal electric power generation lies at the NW of the Mt. Sabalan (Ghaedrahmati et al. 2013). The area has been under geoscientific exploration studies since 1978 (Fotouhi 1995).

Ardebil geology is diverse and complicated and has a long evolution history. These features discriminate the area from the other part of Iran. North of Ardabil is covered with older alluvial, Clay, Marl and tuff intercalations. Surrounding region around Mt. Sabalan is characterized by the predominance of Quaternary terrace deposits (Dizu Formation); altered postcaldera Pleistocene trachyandesitic domes, flows and lahars (Kasra Formation); unaltered syn-caldera Pleistocene trachydacite to trachyandesitic flows, domes and lahars (Toas Formation); and pre-caldera trachyandesitic lavas, tuffs and pyroclastics (Valhazir Formation) (Fig. 2). The geologic study of the Northwest of Sabalan confirmed that there are two major types of structural setting: a set of linear faults and several inferred faults (SKM, Sinclair Knight Merz 2005); the faults strike predominantly towards the northwest and northeast (KML 1998). A northeast-southwest structural trend is dominant in the south of Ardebil city. The main geological units exposed in this area include Miocene's altered tuff, tuff breccia, pumice, travertine, sandstone, shale, marl and conglomerate and Eocene's olivine basalt and trachybasalt which overlay volcanic breccia and trachyandesite of Eocene age.

However, the structural trend changes to northwestsoutheast direction in the further southern parts. This area geologically contains a sedimentary sequence including Cretaceous limestone, Jurassic's shale and sandstone with intercalation of dolomite which overlain by Eocene's volcanic 




Fig. 1 Sabalan geothermal area 



Fig. 2 Geologic map of the Sabalan geothermal field (modified from Ghaedrahmati et al. 2013)

breccia and trachyandesitic, trachybasaltic lava breccia and lava flows of Quaternary age.

\section{Data and methods}

Aeromagnetic data of the area was obtained from the Geological Survey of Iran. This data was corrected for the International Geomagnetic Reference Field (IGRF 1976). This data was collected in 1974-1975.

In this study, the centroid depth and forward modelling of the spectral peak methods of the aeromagnetic data were used to determine CPD.

Bhattacharyya and Leu (1977) presented a method for determining the centroid of rectangular parallel piped sources, which it had been used in their earlier study (Bhattacharyya and Leu 1975) to investigate the Curie depths of Yellowstone Park. This method was further developed by Okubo et al. (1985) who combined and expanded the ideas of the methods to the purpose of geothermal exploration. If the magnetization of a set of two-dimensional (2D) bodies is completely random and uncorrelated, the radial average of the power density spectra of the total field anomaly, $p(k)$, could be simplified as follows (Blakely 1995; Stampolidis et al. 2005):

$P(k)=A_{1} e^{-2|k| Z_{t}}\left(1-e^{-|k|\left(Z_{\mathrm{b}}-Z \mathrm{t}\right)}\right)^{2}$ where $A_{1}$ is a constant and $Z_{\mathrm{t}}$ and $Z_{\mathrm{b}}$ represent the depths to the top and bottom of the magnetic body, respectively. $k$ denotes the wave number of the magnetic field.

According to Okubo et al. (1985), CPD $\left(Z_{\mathrm{b}}\right)$ can be obtained in two steps. Firstly, the centroid depth $\left(Z_{0}\right)$ of the deepest magnetic source is estimated from the slope of the longest wavelength part of the spectrum divided by the wave number using the following equation (Nwankwo and Shehu 2015):

$\ln \left(\frac{P(k)^{1 / 2}}{k}\right)=A-|k| Z_{0}$

where $P(k)$ is the power density spectrum and $A$ represents a constant.

The depth to the top of the magnetic source is similarly derived from the slope of high wave number portion of the power spectrum as follows (Nwankwo and Shehu 2015):

$\ln \left(P(k)^{1 / 2}\right)=B-|k| Z_{t}$

where $B$ is a constant.

The depth to the magnetic bottom is then obtained from $Z_{\mathrm{b}}=2 Z_{0}-Z_{\mathrm{t}}$. 


\section{Forward modelling of the spectral peak method}

Ravat (2004); Finn and Ravat (2004); Ross et al. (2004) and Ravat et al. (2007) proposed forward modelling of the spectral peak to better estimate the bottom depth by using Eq. 4 .

$P(k)=C\left(e^{-|k| Z_{t}}-e^{-|k| Z_{b}}\right)^{2}$

where the constant $C$, non-depth-dependent term, can be adjusted to move the modelled curve up or down to fit the observed peak. Location of the spectral peak and the slope in the high wave number range are controlled by $Z_{\mathrm{b}}$ and $Z_{\mathrm{t}}$, respectively. The combination of both $Z_{\mathrm{t}}$ and $Z_{\mathrm{b}}$ controls the slope immediately adjacent to the peak (Ravat et al. 2007). The advantage of forward modelling is that it allows one to fit iteratively the position and the width of the peak and match the adjacent part of the slope more precisely and explore the model space. Based on the fit of modelled spectra with the observed, one may accept or reject the results more confidently in this overall subjective process of fitting specific parts of the spectra.

In both of these methods, CPD is computed in three steps: (1) dividing the total magnetic field map into overlapping subregions, (2) calculating the logarithm of power spectrum for each region and (3) considering $Z_{\mathrm{b}}=2 Z_{0}-Z_{\mathrm{t}}$ equation for centroid method and calculating the basal depth or fit of the modelled spectra with the observed spectrum and calculating $Z_{\mathrm{t}}$ and $Z_{\mathrm{b}}$

Fig. 3 Selection of overlapping blocks on the RTP map. Solid circles indicate centres of blocks
Having found the CPD, the heat flow values of the region can be calculated using the following equation (Turcotte and Schubert 1982):

$q=k \frac{\partial T}{\partial Z}$

where $q$ is the heat flow, $k$ represents the coefficient of thermal conductivity, and $\frac{\partial T}{\partial Z}$ denotes the thermal gradient.

\section{Data processing and analysis}

Selecting the optimal dimensions of the sub-regions is very important. The limited depth extent of the crustal magnetization would be visible in magnetic maps, covering less than $100 \times 100 \mathrm{~km}$ (Maus et al. 1997). Okubo et al. $(1985,2003)$ suggested the optimal dimensions of the investigated square window to be about ten times the actual target depth (Hisarli et al. 2011). Connard et al. (1983) divided a magnetic data of the Cascade Range, central Oregon, into overlapping blocks $(77 \times 77 \mathrm{~km})$ and calculated the radially average power spectrum for each block. Tanaka et al. (1999) divided the East and Southeast Asia into sub-region data (approximately $200 \times 200 \mathrm{~km}$ ) and estimated the power density spectra for each region. Blakely (1988) divided the area of Nevada into blocks $(120 \times 120 \mathrm{~km})$ in terms of magnetic or aeromagnetic data and mapped the CDP of Nevada state.

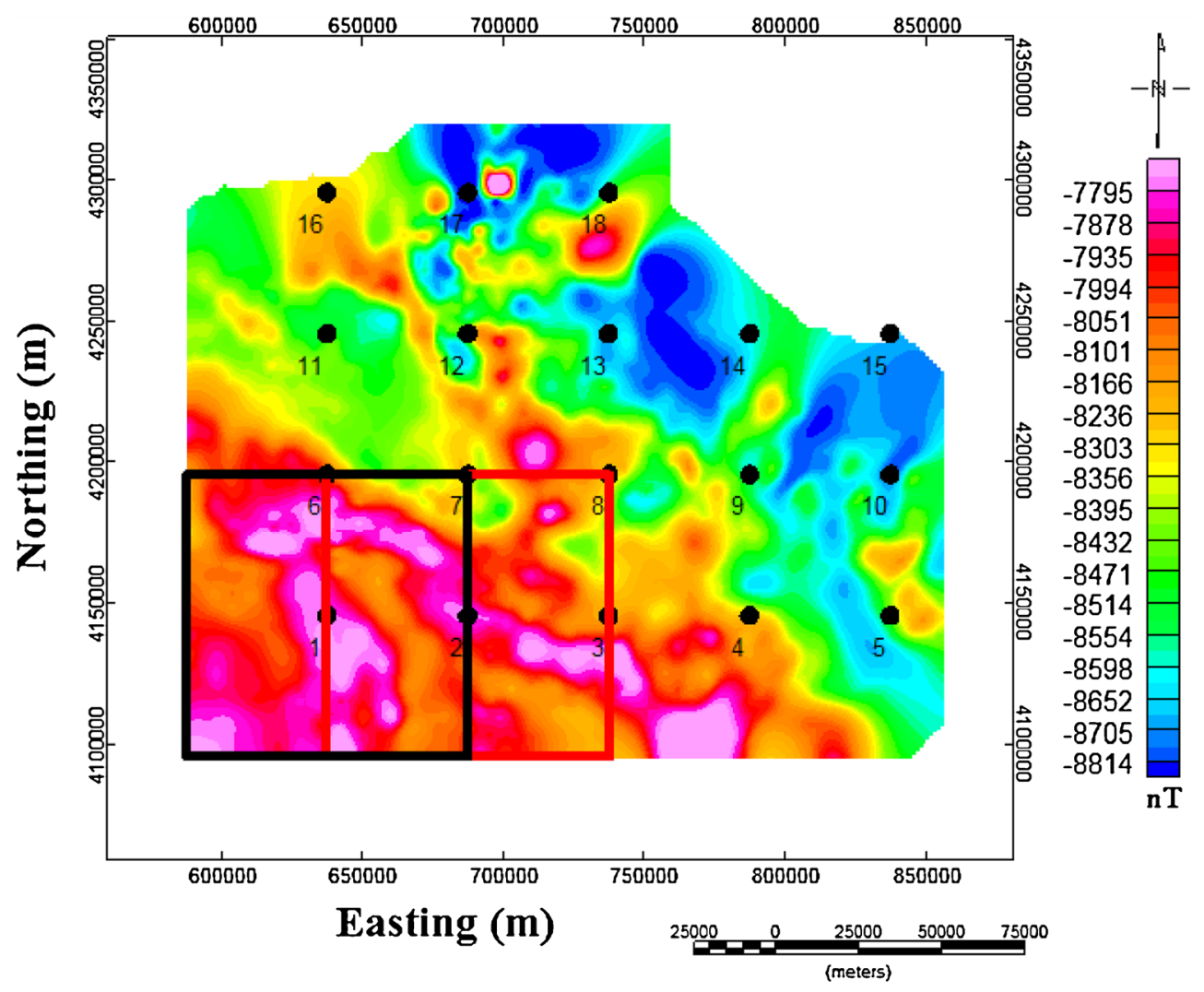


In the present study, the reduced-to-pole (RTP) aeromagnetic data were divided into 18 overlapping blocks of sizes of $100 \times 100 \mathrm{~km}$ (overlapped $50 \%$ with the adjacent blocks) (Fig. 3). It is widely acknowledged that the utilization of a small window width may be a fundamental error in the application of spectral methods for aeromagnetic interpretation (Nwankwo and Shehu 2015). If the source bodies have bases deeper than $L / 2 \pi$, they may not be appropriately resolved by spectral method (Shuey et al. 1977). Therefore, data window of $100 \times 100 \mathrm{~km}$ possibly will satisfactorily resolve only depth information to a depth of $15 \mathrm{~km}$. This window size is based on the fact that a computer code which has been written to determine a proper block size for calculating the radial power spectra considers different window sizes varying from 50 to $400 \mathrm{~km}$ with a $10-\mathrm{km}$ increasing step size. The absence of a peak indicates that the peak lies at wave numbers lower than the minimum resolved wave number; hence, a larger window size is needed to compute the radial power spectrum and detect the bottom of magnetic sources. The results show that a peak is observed for some window sizes, but it shifts and eventually disappears with increasing window size. The appropriate block size of $100 \times 100 \mathrm{~km}$ was then chosen so that the maximum spectral peaks of the aeromagnetic data could be visible in the power spectrum. However, few blocks with CPD more than $13 \mathrm{~km}$ were recomputed with data window increased to $200 \times 200 \mathrm{~km}$. The $2 \mathrm{D}$ power spectrum of aeromagnetic data for each block was then computed using the Oasis montaj software with fast Fourier transform (FFT) method. Then, the effects of very deep regional structures were removed using a first-order trend filter for each block, and grids were expanded by $10 \%$ using the maximum entropy method to make the edges continuous. The biggest advantage of $2 \mathrm{D}$ power spectrum is that the depth of sources is easily determined by measuring the slope of the power spectrum when the centroid method is used (Saleh et al. 2012).

\section{Results and discussion}

This is the first time that spectral analysis of the aeromagnetic data is being used to assess the thermal structure of the crust in Ardebil province and mainly around Mt. Sabalan area. So, as a representative example, the power spectrum plots for block no. 17 in the north Sabalan are shown in Fig. 4. Once the depth to the top of this block $\left(Z_{\mathrm{t}}=1.2 \mathrm{~km}\right)$ was estimated using Eq. 3 and Fig. 4a, then Eq. 2 was applied to estimate the centroid depth $\left(Z_{0}=7.8 \mathrm{~km}\right)$ as shown by Fig. $4 \mathrm{~b}$. Finally, CPD was calculated using $Z_{\mathrm{b}}=2 Z_{0}-Z_{\mathrm{t}}=14.4 \mathrm{~km}$. Besides, Fig. $4 \mathrm{c}$ shows an example of the spectral peak forward modelling method of the same block. In this figure, the calculated power spectrum was fitted iteratively with the measured power spectrum using MATLAB software (Version 7.12.0.635,
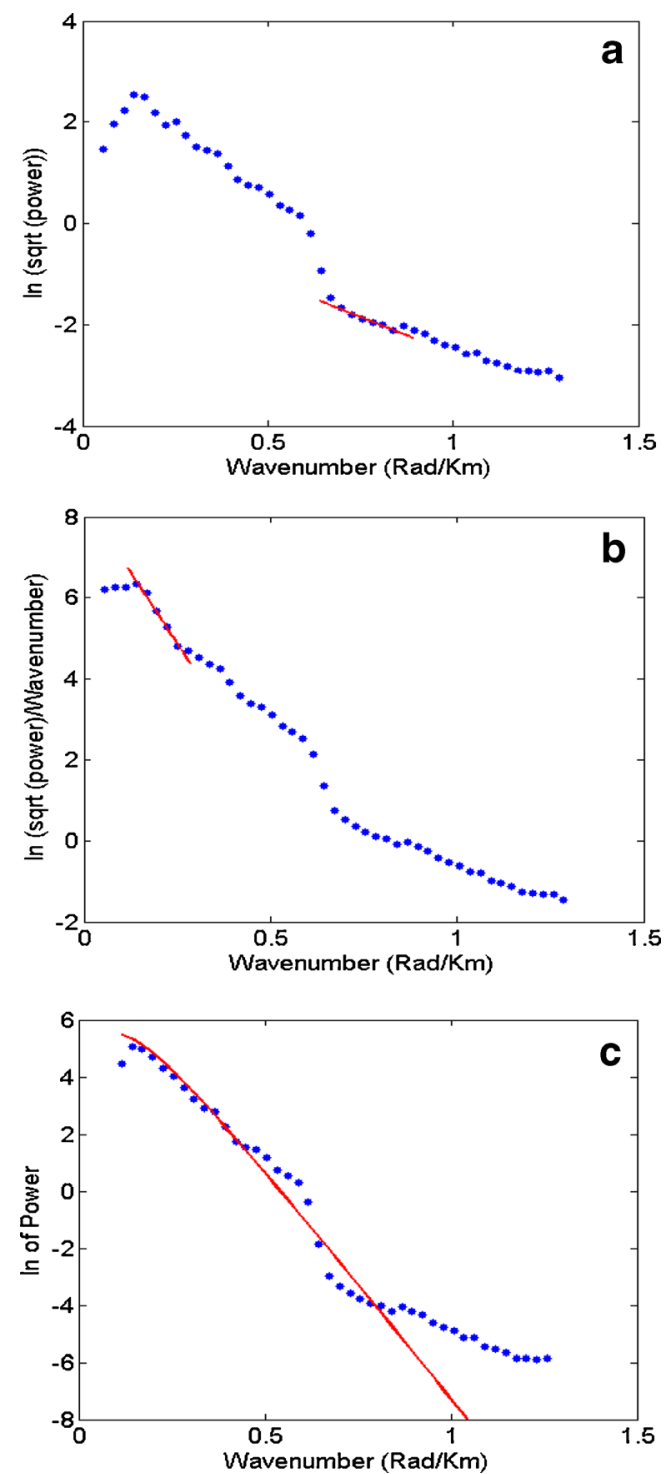

Fig. 4 Examples of power spectra for the block no. 17. a The depth of the top $Z_{\mathrm{t}}=1.2 \mathrm{~km}$ is obtained by fitting a straight line through the second longest wavelength spectral segment. $\mathbf{b}$ The depth to centroid $Z_{0}=7.8 \mathrm{~km}$ is obtained by fitting a straight line through the longest wavelength portion of the spectra. The Curie point depth for this block is $Z_{\mathrm{b}}=2 Z_{0}-Z_{\mathrm{t}}=14.4 \mathrm{~km}$. c The blue line represents the measured power spectrum, and the red line is the result of forward modelling: its depth to the top is $4.1 \mathrm{~km}$, and bottom is $14.1 \mathrm{~km}$

R2011a). By using this method, the top depth of this block $\left(Z_{\mathrm{t}}=4.1 \mathrm{~km}\right)$ and Curie depth $\left(Z_{\mathrm{b}}=14.1 \mathrm{~km}\right)$ were determined. The obtained results for the other blocks applying the centroid depth and forward modelling of the spectral peak methods are given by Tables 1 and 2, respectively.

Figure 5 also shows the CPD map of the study area for two methods: (a) centroid method and (b) forward modelling of the spectral peak method. In these figures, two shallow CPD zones were observed. The first shallow CPD is identified in the west and northwest of the Mt. Sabalan, and the second zone is seen in the bottom left corner of the map which is 
Table 1 Estimated CPD, geothermal gradients and heat flow by applying the centroid depth method for the 18 blocks in the study area

\begin{tabular}{|c|c|c|c|c|c|c|c|}
\hline \multirow{2}{*}{$\begin{array}{l}\text { Block } \\
\text { number }\end{array}$} & \multicolumn{2}{|c|}{ Coordinates (UTM) } & \multirow{2}{*}{$\begin{array}{l}\text { Depth to centroid } \\
(\mathrm{km})\end{array}$} & \multirow{2}{*}{$\begin{array}{l}\text { Depth to top } \\
(\mathrm{km})\end{array}$} & \multirow[t]{2}{*}{$\mathrm{CPD}(\mathrm{km})$} & \multirow{2}{*}{$\begin{array}{l}\text { Geothermal } \\
\text { gradient }\left({ }^{\circ} \mathrm{C} / \mathrm{km}\right)\end{array}$} & \multirow{2}{*}{$\begin{array}{l}\text { Heat flow } \\
\left(\mathrm{mW} / \mathrm{m}^{2}\right)\end{array}$} \\
\hline & Easting (m) & Northing (m) & & & & & \\
\hline 1 & $637,367.7$ & $4,145,618$ & 6.3 & 2.6 & 10.0 & 58.0 & 145.0 \\
\hline 2 & $687,367.7$ & $4,145,618$ & 7.4 & 2.5 & 12.3 & 47.2 & 117.9 \\
\hline 3 & $737,367.7$ & $4,145,618$ & 7.2 & 2.4 & 12.0 & 48.3 & 120.8 \\
\hline 4 & $787,367.7$ & $4,145,618$ & 7.8 & 2.7 & 12.9 & 45.0 & 112.4 \\
\hline 5 & $837,367.7$ & $4,145,618$ & 9.1 & 1.7 & 16.5 & 35.2 & 87.9 \\
\hline 6 & $637,367.7$ & $4,195,618$ & 7.9 & 2.4 & 13.4 & 43.3 & 108.2 \\
\hline 7 & $687,367.7$ & $4,195,618$ & 8.8 & 2.6 & 15.0 & 38.7 & 96.7 \\
\hline 8 & $737,367.7$ & $4,195,618$ & 9.1 & 1.9 & 16.3 & 35.6 & 89.0 \\
\hline 9 & $787,367.7$ & $4,195,618$ & 8.9 & 2.2 & 15.6 & 37.2 & 92.9 \\
\hline 10 & $837,367.7$ & $4,195,618$ & 9.5 & 2.1 & 16.9 & 34.3 & 85.5 \\
\hline 11 & $637,367.7$ & $4,245,618$ & 7.8 & 2.2 & 13.4 & 43.3 & 108.2 \\
\hline 12 & $687,367.7$ & $4,245,618$ & 6.9 & 2.4 & 11.4 & 50.9 & 127.2 \\
\hline 13 & $737,367.7$ & $4,245,618$ & 6.8 & 2.3 & 11.3 & 51.3 & 128.3 \\
\hline 14 & $787,367.7$ & $4,245,618$ & 8.2 & 1.8 & 14.6 & 39.7 & 99.3 \\
\hline 15 & $837,367.7$ & $4,245,618$ & 8.1 & 1.6 & 14.6 & 39.7 & 99.3 \\
\hline 16 & $637,367.7$ & $4,295,618$ & 8.9 & 1.9 & 15.9 & 36.5 & 91.2 \\
\hline 17 & $687,367.7$ & $4,295,618$ & 7.8 & 1.2 & 14.4 & 40.3 & 100.7 \\
\hline 18 & $737,367.7$ & $4,295,618$ & 9.2 & 2.2 & 16.2 & 35.8 & 89.5 \\
\hline
\end{tabular}

located mainly in the East Azerbaijan province. In the centroid method (Table 1), block no. 1 has the shallowest CPD (10 km) and block no. 10 has the deepest CPD $(16.9 \mathrm{~km})$. Whereas, by applying the forward modelling of spectral peak method, the shallowest and deepest CPDs are assigned for blocks no. 1 and no. 18 , respectively (Table 2 ).

Table 2 Estimated CPD, geothermal gradients and heat flow by using the forward modelling of spectral peak method for the 18 blocks in the study area

\begin{tabular}{|c|c|c|c|c|c|c|}
\hline \multirow{2}{*}{$\begin{array}{l}\text { Block } \\
\text { number }\end{array}$} & \multicolumn{2}{|c|}{ Coordinates (UTM) } & \multirow{2}{*}{$\begin{array}{l}\text { Depth to top } \\
(\mathrm{km})\end{array}$} & \multirow[t]{2}{*}{$\mathrm{CPD}(\mathrm{km})$} & \multirow{2}{*}{$\begin{array}{l}\text { Geothermal } \\
\text { gradient }\left({ }^{\circ} \mathrm{C} / \mathrm{km}\right)\end{array}$} & \multirow{2}{*}{$\begin{array}{l}\text { Heat flow } \\
\left(\mathrm{mW} / \mathrm{m}^{2}\right)\end{array}$} \\
\hline & Easting (m) & Northing (m) & & & & \\
\hline 1 & $637,367.7$ & $4,145,618$ & 6.5 & 10.5 & 55.2 & 138.1 \\
\hline 2 & $687,367.7$ & $4,145,618$ & 5.3 & 11.8 & 49.2 & 122.9 \\
\hline 3 & $737,367.7$ & $4,145,618$ & 7.1 & 13.0 & 44.6 & 111.5 \\
\hline 4 & $787,367.7$ & $4,145,618$ & 6.7 & 12.2 & 47.5 & 118.9 \\
\hline 5 & $837,367.7$ & $4,145,618$ & 7.0 & 15.0 & 38.7 & 96.7 \\
\hline 6 & $637,367.7$ & $4,195,618$ & 6.3 & 13.5 & 43.0 & 107.4 \\
\hline 7 & $687,367.7$ & $4,195,618$ & 5.8 & 16.5 & 35.2 & 87.9 \\
\hline 8 & $737,367.7$ & $4,195,618$ & 6.5 & 17.5 & 33.1 & 82.9 \\
\hline 9 & $787,367.7$ & $4,195,618$ & 6.1 & 15.2 & 38.2 & 95.4 \\
\hline 10 & $837,367.7$ & $4,195,618$ & 6.8 & 16.2 & 35.8 & 89.5 \\
\hline 11 & $637,367.7$ & $4,245,618$ & 5.2 & 12.2 & 47.5 & 118.9 \\
\hline 12 & $687,367.7$ & $4,245,618$ & 4.9 & 10.6 & 54.7 & 136.7 \\
\hline 13 & $737,367.7$ & $4,245,618$ & 5.0 & 10.9 & 53.2 & 133.0 \\
\hline 14 & $787,367.7$ & $4,245,618$ & 5.8 & 15.3 & 37.9 & 94.8 \\
\hline 15 & $837,367.7$ & $4,245,618$ & 6.3 & 15.9 & 36.5 & 91.2 \\
\hline 16 & $637,367.7$ & $4,295,618$ & 5.5 & 14.8 & 39.2 & 98.0 \\
\hline 17 & $687,367.7$ & $4,295,618$ & 4.1 & 14.1 & 41.1 & 102.8 \\
\hline 18 & $737,367.7$ & $4,295,618$ & 5.6 & 18.6 & 31.2 & 78.0 \\
\hline
\end{tabular}


Fig. 5 The CPD maps of the study area: a centroid method and b forward modelling of the spectral peak method (contour interval is $0.5 \mathrm{~km}$ ), thermal spring (red solid circle), drilled well (black square) and Mt. Sabalan (yellow solid triangle) a

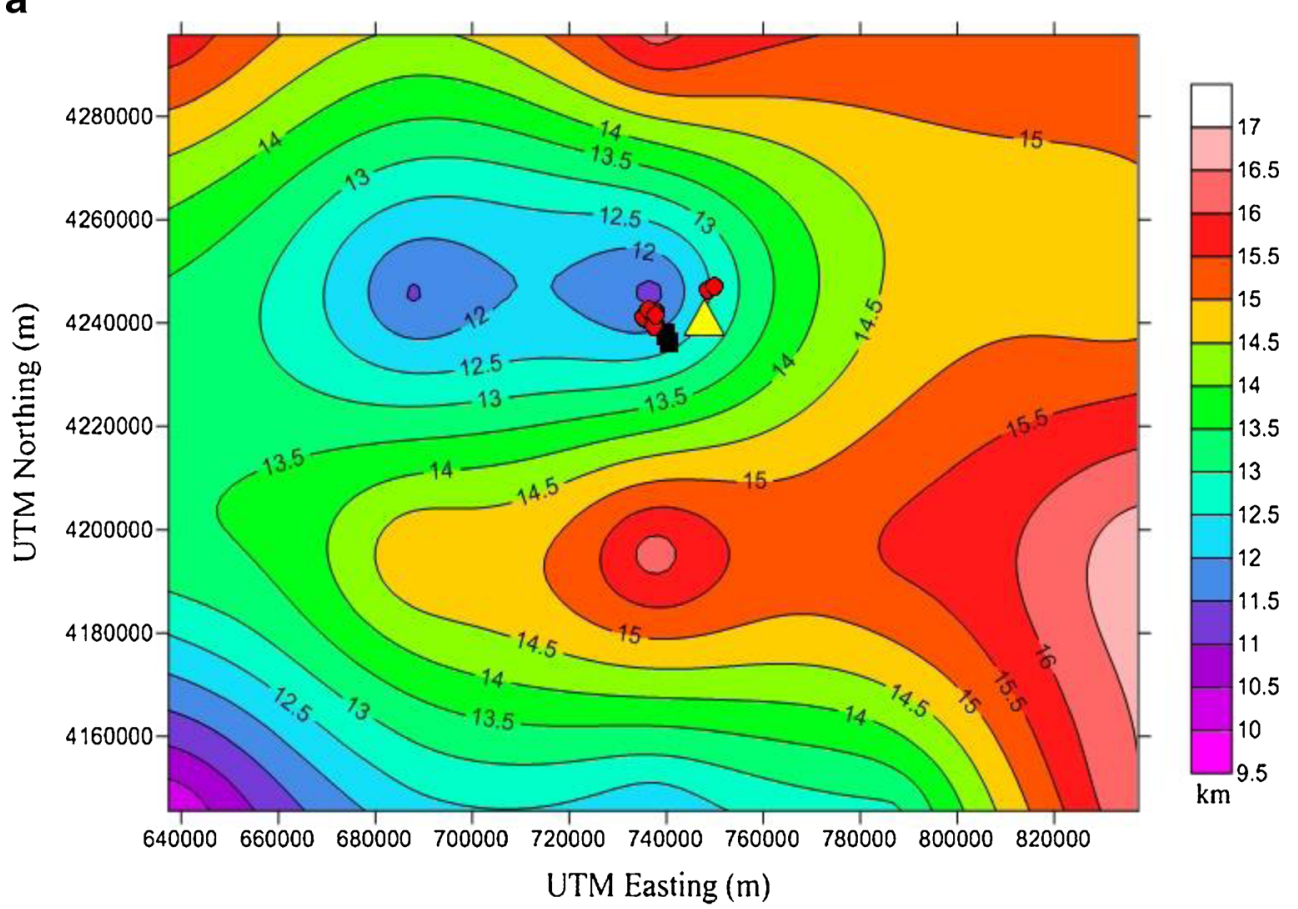

b

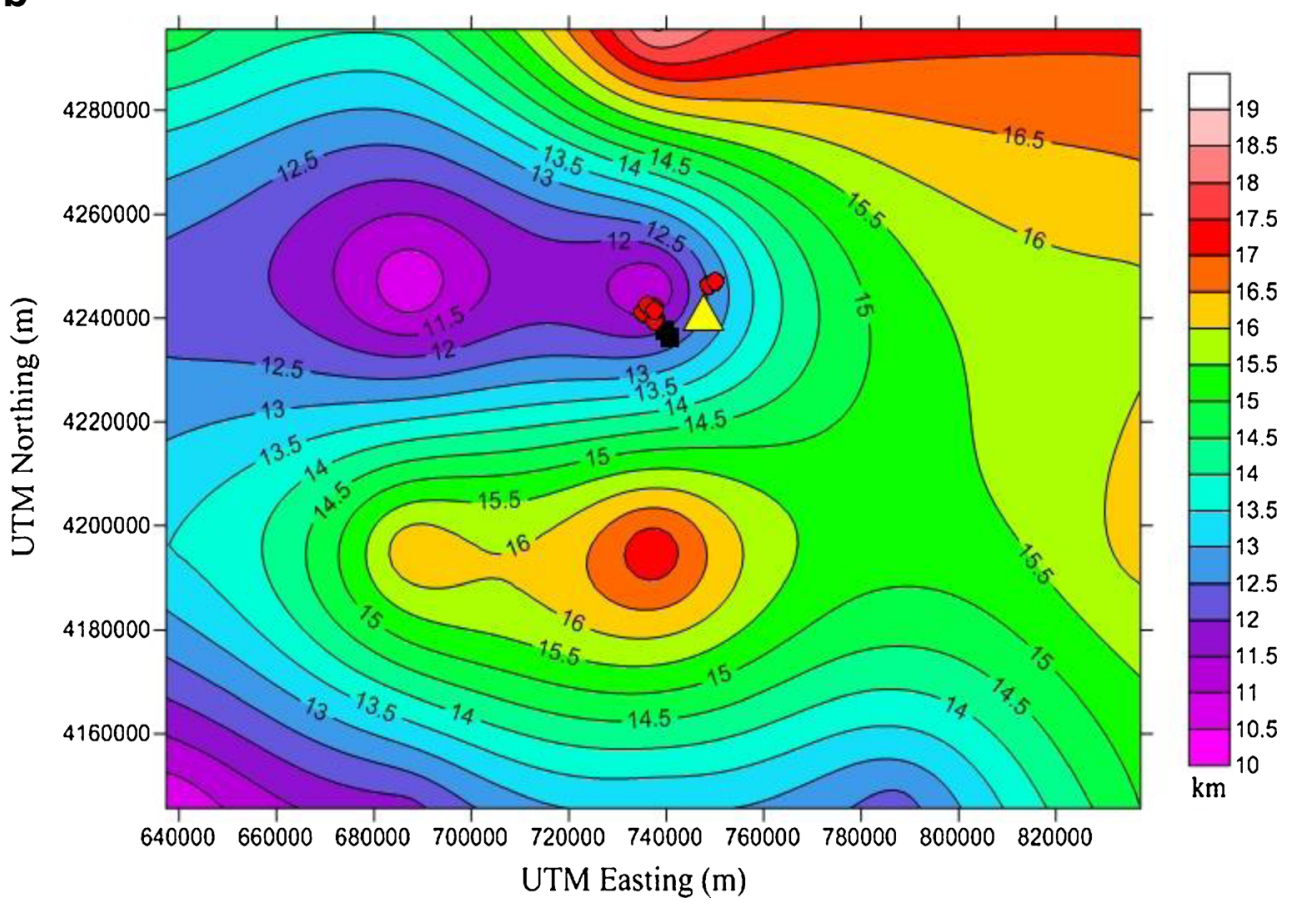

For determination of the surface heat flow, the value of thermal conductivity $(k)$ is given $2.5 \mathrm{Wm}^{-1}{ }^{\circ} \mathrm{C}^{-1}$ according to the average thermal conductivity of the crustal rocks (Stacey 1977). The geothermal gradient of each block was calculated by dividing $580{ }^{\circ} \mathrm{C}$ by the CPD. Heat flow was then calculated by multiplying the geothermal gradient by the thermal conductivity. Equation 5 was finally applied to estimate the flow map of the study area (Fig. 6). Figure $6 \mathrm{a}$ and Table 1 illustrate the lowest heat flow value $\left(85.5 \mathrm{MW} / \mathrm{m}^{2}\right)$ for block no. 10 and the highest heat flow value $\left(145 \mathrm{MW} / \mathrm{m}^{2}\right)$ for block no. 1. In Fig. $6 \mathrm{~b}$ and Table 2, one can see the highest heat flow value of $138.1 \mathrm{MW} / \mathrm{m}^{2}$ occurring in block no. 1 and the lowest heat flow value of $78.0 \mathrm{MW} / \mathrm{m}^{2}$ in block no. 18. Tables 1 and 2 give the 
Fig. 6 Heat flow maps in the study area: a centroid method and b forward modelling of the spectral peak method (contour interval is $5 \mathrm{~mW} / \mathrm{m}^{2}$ ), thermal spring (red solid circle), drilled well (black square) and Mt. Sabalan (yellow solid triangle)


calculated CPD, heat flow and the geothermal gradient values for all 18 blocks. The maps in Fig. 7 show the geothermal gradient estimates each of these two methods. It can be observed that a region with high temperature gradient (Fig. 7a, 7b) and high heat flow (Fig. 6a, 6b) is associated with the shallow CPD (Fig.5a, b). Results of the both methods are rather the same. Also, the shallowest $\mathrm{CPD}$, highest heat flow value and maximum thermal gradient are shown in the west, northwest and the southwest of study area. These results are confirmed by the available well data, gravity and magnetotelluric measurements. The CPD strongly varies according to the geological conditions (Ross et al. 2006). The CPDs at volcanic and geothermal areas are shallower than $10 \mathrm{~km}$ (Obande et al. 2014). Heat flow of about $80-100 \mathrm{MW} / \mathrm{m}^{2}$ indicates geothermal anomalous conditions (Jessop et al. 1976). For the 
Fig. 7 Gradient maps in the study area: a centroid method and b forward modelling of the spectral peak method (contour interval is $2{ }^{\circ} \mathrm{C} / \mathrm{km}$ ), thermal spring (red solid circle), drilled well (black square) and Mt. Sabalan (yellow solid triangle)
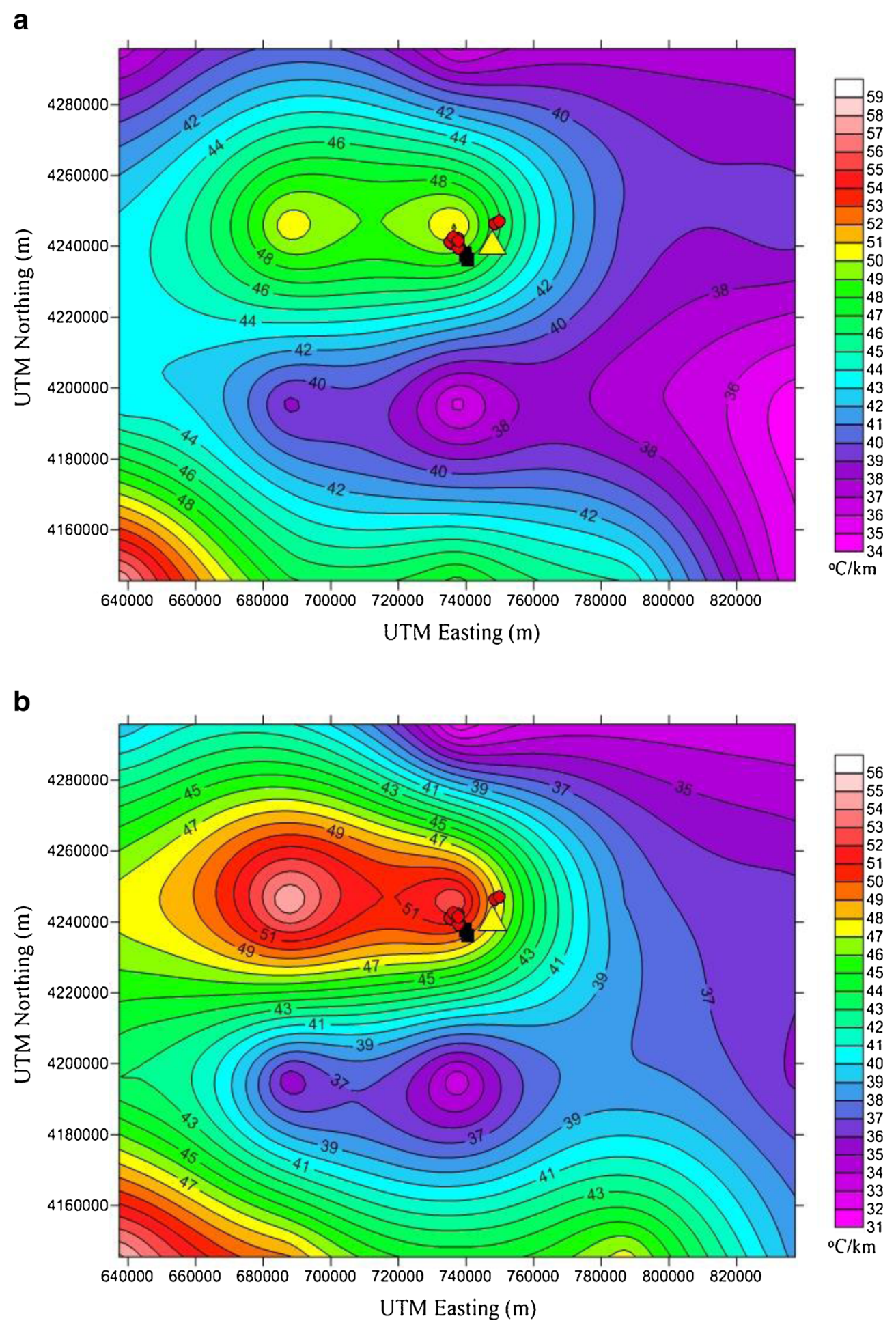

study area and area around Mt. Sabalan, the geothermal anomalous conditions have been assigned to the most blocks. As a result, the study area is found to have a great energy potential in the west, northwest and the southwest of Mt. Sabalan with a shallow CPD, high geothermal gradient and heat flow.

\section{Conclusions}

An attempt has been made to calculate the depth to bottom of the magnetic sources from the aeromagnetic data in the Ardebil province in NW of Iran using spectral methods. The CDP has been calculated by the centroid depth and forward 
modelling of the spectral peak methods. The results show that CPD varies from $10 \mathrm{~km}$ in the southwest to $18.6 \mathrm{~km}$ in the north and northeast of the study area. The calculated thermal gradient based on the CPD varies from $58.0^{\circ} \mathrm{C} / \mathrm{km}$ in the southwest to $31.2{ }^{\circ} \mathrm{C} / \mathrm{km}$ in the north and east of study area. The corresponding prepared heat flow maps using thermal conductivity and thermal gradients indicate that the highest and lowest heat flow values occurred in southwest $\left(145.0 \mathrm{MW} / \mathrm{m}^{2}\right)$ and north $\left(78.0 \mathrm{MW} / \mathrm{m}^{2}\right)$ and east of the Mt. Sabalan, respectively. According to the shallow calculated CPD and high heat flow values that occur on the west, the northwest and the southwest of the Mt. Sabalan and considering the available geological and some geophysical information, it can be concluded that these areas may have a great potential of geothermal energy. Consequently, it is proposed the results of this study to be integrated in the GIS environment with all available geological, geophysical, geochemical and other information layers. This additional information will facilitate selection of the optimum site for exploration.

Open Access This article is distributed under the terms of the Creative Commons Attribution 4.0 International License (http:// creativecommons.org/licenses/by/4.0/), which permits unrestricted use, distribution, and reproduction in any medium, provided you give appropriate credit to the original author(s) and the source, provide a link to the Creative Commons license, and indicate if changes were made.

\section{References}

Aydin I, Oksum E (2010) Exponential approach to estimate the Curietemperature depth. J Geophys Eng 7:113-125

Bansal AR, Gabriel G, Dimri VP, Krawczyk CM (2011) Estimation of depth to the bottom of magnetic sources by a modified centroid method for fractal distribution of sources: an application to aeromagnetic data in Germany. Geophysics 76(3):11-22

Bhattacharyya BK, Leu LK (1975) Analysis of magnetic anomalies over Yellowstone National Park: mapping of Curie point isothermal surface for geothermal reconnaissance. J Geophys Res 80:4461-4465

Bhattacharyya BK, Leu LK (1977) Spectral analysis of gravity and magnetic anomalies due to rectangular prismatic bodies. Geophysics 41:41-50

Blakely R (1988) Curie temperature isotherm analysis and tectonic implications of aeromagnetic data from Nevada. J Geophys Res 93: $11817-11832$

Blakely RJ (1995) Potential theory in gravity and magnetic applications, Cambridge Univ. Press, Cambridge

Connard G, Couch R, Gemperle M (1983) Analysis of aeromagnetic measurements from the Cascade Range in central Oregon. Geophysics 48:376-390

Dolmaz MN, Ustaomer T, Hisarli ZM, Orbay N (2005) Curie point depth variations to infer thermal structure of the crust at the African-Eurasian convergence zone, SW Turkey. Earth, Planets and Space 57:373-383

Eletta BE, Udensi EE (2012) Investigation of the Curie point isotherm from the magnetic fields of eastern sector of central Nigeria. Geosciences 2(4):101-106

Finn CA, Ravat D (2004) Magnetic depth estimates and their potential for constraining crustal composition and heat flow in Antarctica, EOS, Trans. Am. Geophys. Un, 85(47), Fall Meet. Suppl., Abstract T11A-1236.
Fotouhi M (1995) Geothermal development in Sabalan, Iran. World Geothermal Congress, Italy

Ghaedrahmati R, Moradzadeh A, Fathianpour N, Lee SK, Porkhial S (2013) 3-D inversion of MT data from the Sabalan geothermal field, Ardabil, Iran. J Appl Geophys 93:12-24

Hisarli ZM, Dolmaz MN, Okyar M, Etiz A, Orbay N (2011) Investigation into regional thermal structure of the Thrace Region, NW Turkey, from aeromagnetic and borehole data. Stud Geophys Geod 56:269-291

Jessop AM, Hobart MA, Sclater JG (1976) The world heat flow data collection 1975, Geothermal Services of Canada. Geothermal Service 50:55-77

Karastathis VK, Papoulia J, Di Fiore B, Makris J, Tsambas A, Stampolidis A, Papadopoulos GA (2010) Exploration of the deep structure of the central Greece geothermal field by passive seismic and Curie depth analysis, 72nd EAGE Conference \& Exhibition incorporating SPE EUROPEC 2010, Barcelona, Spain, 14-17 June 2010, paper Po12.

KML (1998) Sabalan geothermal project, stage 1-surface exploration, final exploration report. Kingston Morrison Limited Co., report 2505-RPTGE-003 for the Renewable Energy Organization of Iran, Tehran, p. 83

Maus S, Gordon D, Fairhead D (1997) Curie temperature depth estimation using a self-similar magnetization model. Geophys J Int 129:163-168

Nwankwo LI, Shehu AT (2015) Evaluation of Curie-point depths, geothermal gradients and near-surface heat flow from high-resolution aeromagnetic (HRAM) data of the entire Sokoto Basin, Nigeria. J Volcanol Geotherm Res 305:45-55

Obande GE, Lawal KM, Ahmed LA (2014) Spectral analysis of aeromagnetic data for geothermal investigation of Wikki Warm Spring, north-east Nigeria. Geothermics 50:85-90

Okubo Y, Graf RJ, Hansent RO, Ogawa K, Tsu H (1985) Curie point depths of the island of Kyushu and surrounding areas Japan. Geophysics 53:481-494

Okubo Y, Matsushima J, Correia A (2003) Magnetic spectral analysis in Portugal and its adjacent seas. Phys Chem Earth 28:511-519

Ravat D (2004) Constructing full spectrum potential-field anomalies for enhanced geodynamical analysis through integration of surveys from different platforms (INVITED), EOS, Trans. Am. Geophys. Un., 85(47), Fall Meet. Suppl., Abstract G44A-03.

Ravat D, Pignatelli A, Nicolosi I, Chiappini M (2007) A study of spectral methods of estimating the depth to the bottom of magnetic sources from near-surface magnetic anomaly data. Geophys J Int 169:421-434

Ross HE, Blakely RJ, Zoback MD (2004) Testing the utilization of aeromagnetic data for the determination of Curie-isotherm depth, EOS, Trans. Am. Geophys. Un., 85(47), Fall Meet. Suppl., Abstract T31A-1287.

Ross HE, Blakely RJ, Zoback MD (2006) Testing the use of aeromagnetic data for the determination of Curie depth in California. Geophysics 71(5):L51-L59

Saleh S, Salk M, Pamukcu O (2012) Estimating Curie point depth and heat flow map for northern Red Sea rift of Egypt and its surroundings, from aeromagnetic data, Pure Appl Geophys

Shuey RT, Schellinger DK, Tripp AC, LB A (1977) Curie depth determination from aeromagnetic spectra. Geophys J R Astron Soc 50:75-101

SKM (Sinclair Knight Merz) 2005 Resource review of the Northwest Sabalan geothermal project. Report submitted to SUNA. (61p).

Stacey FD (1977) Physics of the Earth, 2nd edn. Wiley, New York, p. 414

Stampolidis A, Kane I, Tsokas GN, Tsourlos P (2005) Curie point depths of Albania from ground total field magnetic data. Survey Geophysics 26:461-480

Tanaka A, Okubo Y, Matsubayashi O (1999) Curie point depth based on spectrum analysis of magnetic anomaly data in East and Southeast Asia. Tectonophysics 306:461-470

Tselentis GA (1991) an attempt to define curie depths in Greece from aeromagnetic and heat flow data. PAGEOPH 136:87-101

Turcotte DL, Schubert G (1982) Geodynamics: applications of continuum physics to geological problems. Wiley, New York, p. 450 